\title{
Fabrication of Composite Material with Pd Nanoparticles and Graphene on Nickel Foam for Its Excellent Electrocatalytic Performance
}

\author{
Yanmei Shen ${ }^{1} \cdot$ Shixiang $\mathrm{Lu}^{1} \cdot$ Wenguo Xu ${ }^{1} \cdot$ Anqi $\mathrm{Lv}^{1} \cdot$ Ziwen Wang $^{1} \cdot$ Hongtao Wang ${ }^{1} \cdot$ Guoxiao Liu $^{1} \cdot$ Yan Zhang $^{2}$ \\ Published online: 14 June 2020 \\ (C) The Author(s) 2020
}

\begin{abstract}
Incorporation of precious metallic nanoparticles onto a carbon support material is used to obtain an electrocatalyst for ethanol oxidation. A composite material of spherical palladium nanoparticles (Pd NPs), reduced graphene oxide (rGO), and polydopamine (PDA) on three-dimensional nickel foam (NF) substrate ( $\mathrm{Pd} / \mathrm{rGO} / \mathrm{PDA} @ \mathrm{NF})$ has been synthesized for ethanol electrocatalysis. The Pd nanoparticles were obtained via reduction of precursor $\mathrm{K}_{2} \mathrm{PdCl}_{4}$ using ascorbic acid at $60{ }^{\circ} \mathrm{C}$ for 80 min. The rGO with large specific surface area was used in catalysts to provide large amounts of active sites for Pd NPs. Meanwhile, Pd NPs as an effective ingredient in catalyst exhibited excellent electrochemical activity of ethanol oxidation. Local surface plasmon resonance was carried out to determine the optimal concentration of precursor $\mathrm{K}_{2} \mathrm{PdCl}_{4}$ aqueous solution, and the absorbance peak of Pd NPs was found at about 340-370 nm by UV-visible spectroscopy. An enhanced property of the composite material Pd/rGO/PDA@NF was demonstrated to catalyze the ethanol oxidation reaction in alkaline electrolyte solution. A higher ratio of forward scan peak current intensity $\left(I_{\mathrm{f}}\right)$ to reverse scan peak current intensity $\left(I_{\mathrm{b}}\right)$ was 1.59 , which demonstrated the significant anti-poison effect to carbonaceous intermediates of the Pd/rGO/PDA@NF. The value of $I_{\mathrm{f}}$ can maintain $90.6 \%$ after 400 cycles, indicating the higher cycling stability and better electrocatalytic performance toward ethanol oxidation.
\end{abstract}

Keywords Pd nanoparticles $\cdot$ Ethanol electrocatalysis $\cdot$ Graphene $\cdot$ Polydopamine $\cdot$ Nickel foam

\section{Introduction}

Nowadays, direct ethanol fuel cells (DEFCs) have received great attention owing to the higher energy density and less environmental pollution than traditional fossil fuels [1]. Ethanol, as the hydrogen-rich and non-toxic liquid in DEFCs, exhibits more advantages, such as low toxicity and

Electronic supplementary material The online version of this article (https://doi.org/10.1007/s12678-020-00611-0) contains supplementary material, which is available to authorized users.

Shixiang Lu

shixianglu@bit.edu.cn

Wenguo Xu

xuwg60@bit.edu.cn

1 School of Chemistry and Chemical Engineering, Beijing Institute of Technology, Beijing 100081, People's Republic of China

2 State Grid Corp of China Shandong Electric Power Research Institute, Jinan 250003, People's Republic of China environmental compatibility [2]. Therefore, DEFCs have become clean and high energy sources for sustainable fuel, in which the effective ethanol electro-oxidation reaction is one of the major factors affecting cells property [3].

A great electrocatalyst in ethanol electrochemical oxidation reaction of DEFCs can provide excellent electrocatalytic performance for high energy conversion efficiency and low toxicity [4]. Accordingly, the noble metallic materials have been synthesized to be used as efficient ingredients in electrocatalyst for ethanol oxidation reaction (EOR). The palladium $(\mathrm{Pd})$-based electrocatalysts will promise to become the substitute of platinum (Pt)-based catalysts because Pd can improve the activity, stability, and good tolerance against carbon intermediate species during EOR process [5, 6]. Meanwhile, Pd-based electrocatalyst has demonstrated the better ability to break C-C bond of ethanol in alkaline media as compared with Pt-based catalyst [7]. Moreover, the high cost and limited supply of Pt compose the major obstacle to the development of electrocatalyst for fuel cells [8]. The abundance of Pd on the Earth's crust is 200 times more than Pt, and the relatively low price of Pd makes it suitable for broad-scale fuel cell 
applications [7]. Actually, the Pt-free electrocatalysts like Pd have attracted attention for EOR in alkaline media because of their excellent electroactivity, rapid reaction kinetics, and the probability of using carbon material support to reduce the load of Pd nanoparticles (NPs) [9]. In our days, Pd NPs in catalysts are the most popular and extensive for EOR because they can exist increased surface area and considerable edges and corner atoms to improve the catalytic performance [10]. Meanwhile, Pd NPs can absorb more hydrogen than bulk Pd materials, which indicate the great electrochemical performance of $\mathrm{Pd}$ NPs $[11,12]$. Therefore, these attractive properties of Pdbased electrocatalysts for ethanol oxidation provide the justification for the choice of the study. However, the efficiency and activity of Pd-based catalysts still have some restrictions for DEFCs, including that Pd NPs would aggregate and then lead to low catalytic activity because of the high surface energies [13]. To improve electrocatalytic activity and decrease the aggregation of Pd-based catalysts, many methods have been proposed in some literatures, such as making single metal into alloying catalysts [14], changing the morphologies of metal NPs [15], synthesizing composites based on different supporting materials [16]. Nickel foam (NF) also can be used as both an electrocatalyst in itself and as a Pt electrocatalyst support material for its open-pore structures, high specific surface areas, and good stability in a range of different electrolytes, including strongly alkaline conditions [17-19].

Graphene oxide (GO), as a two-dimensional nanosheet material, possesses excellent high conductivity, high specific surface area, and high carrier mobility and thermal stability [20, 21]. Simultaneously, GO also contains many oxygencontaining functional groups as nucleation centers which can provide abundant active sites for NPs and achieve distinguished functions in organic chemistry, electrochemistry, and nanotechnology [21,22]. These excellent properties make GO become an outstanding and popular substitute to replace the conventional carbon support materials for wide application [20]. Additionally, the reduction of GO (rGO) was obtained by many methods, such as thermal, light, and chemical reduction [23].

Furthermore, the localized surface plasmon resonance (LSPR) effect is a significant factor to research the noble metal nanostructures and photochemistry [24]. At present, the metallic NPs upon LSPR excitation are applied in electrochemical reactions [25]. On the other hand, the LSPR effect of Pd NPs can be detected in ultraviolet-visible range [26]. Aasaithambi Kalaiselvi et al. described the apparent LSPR effect of Pd NPs with the absorbance within the peak range of 350 to $400 \mathrm{~nm}$, and the optimized experiment time was observed [27]. And it also displayed the LSPR of Pd NPs with the absorbance $362 \mathrm{~nm}$ by V N Kalpana et al. [28].

In addition, polydopamine (PDA) acts as a suitable adhesive polymeric material that exhibits great conductivity and biocompatibility [29]. PDA was prepared by one-step self- polymerization in an aqueous solution of dopamine under weak alkaline conditions $(\mathrm{pH}=8.5)$ [30]. The existence of functional group $\left(-\mathrm{NH}_{2}\right)$ in PDA causes electrochemically active nitrogen to be doped in the graphene to enhance their conductivity and reduce the accumulation of graphene [31].

In this paper, we presented a simple chemical method and annealing process to synthesize the composite material $(\mathrm{Pd} /$ rGO/PDA@NF) of Pd NPs, rGO, and PDA on nickel foam (NF) substrate for ethanol electrocatalysis. In our work, we used rGO as carbon support material to load Pd NPs. The GO was deposited on the NF by using PDA polymer film through a facile immersing method. The precursor $\mathrm{K}_{2} \mathrm{PdCl}_{4}$ was reduced to Pd NPs by ascorbic acid and the LSPR peak of NPs provided powerfully evidence to determine the concentration of precursor $\mathrm{K}_{2} \mathrm{PdCl}_{4}$ solution. The $\mathrm{GO}$ was reduced to rGO through annealing process while Pd NPs and substrate combined more inseparable. The poisoning resistance to carbonaceous intermediate species and catalytic oxidation activity of Pd/rGO/PDA@NF were researched. The stability of the electrocatalyst was also investigated by electrochemical workstation.

\section{Experimental Sections}

\section{Materials and Reagents}

Nickel foam (NF) was obtained from Kunshan Toll Hui Electronics Technology Co., Ltd. Quartz slice (QS) was obtained from Donghai Alfa Quartz products Co., Ltd. Potassium chloropalladite $\left(\mathrm{K}_{2} \mathrm{PdCl}_{4}, 98 \%\right)$ and dopamine hydrochloride $\left(\mathrm{C}_{8} \mathrm{H}_{11} \mathrm{NO}_{2} \cdot \mathrm{HCl}, 98 \%\right)$ were obtained from Aladdin Industrial Co., Ltd. Ethanol $\left(\mathrm{C}_{2} \mathrm{H}_{5} \mathrm{OH}, \geq 99.7 \%\right)$, potassium hydroxide $(\mathrm{KOH}, \geq 85.0 \%)$, hydrochloric acid $(\mathrm{HCl}$, $36 \sim 38 \%$ ), phosphoric acid $\left(\mathrm{H}_{3} \mathrm{PO}_{4},>85 \%\right)$, sulfuric acid $\left(\mathrm{H}_{2} \mathrm{SO}_{4}, 95 \% \sim 98 \%\right)$, and acetone $\left(\mathrm{CH}_{3} \mathrm{COCH}_{3}, \geq 95 \%\right)$ were obtained from Beijing Fine Chemical Co., Ltd. LAscorbic acid $\left(\mathrm{C}_{6} \mathrm{H}_{8} \mathrm{O}_{6}\right)$ was purchased from Sinopharm Chemical Reagent Co., Ltd. Purified water was utilized in all experiments. All of chemicals used in our work were analytical purity grade and without further purification.

\section{Preparation of Samples}

\section{Synthesis of GO}

The GO was synthesized from graphite by modified Hummers method [32]. A mixture acid with 9:1 volume ratio of $98 \%$ $\mathrm{H}_{2} \mathrm{SO}_{4}$ and $85 \% \mathrm{H}_{3} \mathrm{PO}_{4}$ was added in the $250 \mathrm{~mL}$ threenecked flask with the mixture of graphite powder $(0.75 \mathrm{~g})$ and $\mathrm{KMnO}_{4}$ solid (4.85 g) at ice-water bath. Then the reaction solution was heated and stirred in $50{ }^{\circ} \mathrm{C}$ for $12 \mathrm{~h}$. Then reaction was cooled to room temperature. After that, the mixture 
was poured and stirred into ice (100 g) with dropped $30 \%$ $\mathrm{H}_{2} \mathrm{O}_{2}(0.75 \mathrm{~mL})$. The reaction product was centrifuged to obtain the precursor graphene oxide. The product was washed in succession with $30 \% \mathrm{HCl}$ solution and with $5 \% \mathrm{HCl}$ solution. For each wash, the mixture was centrifuged in $30 \mathrm{~min}$ and the supernatant decanted away. Finally, the product was filtered with a PVDF membrane to make the solution neutral with purified water. The solid obtained on the filter was dried at room temperature before use.

\section{Synthesizing the Composite of Pd NPs, rGO, and PDA on QS (Pd/rGO/PDA@QS)}

In order to analyze the relationship between LSPR peak and the concentration of precursor $\mathrm{K}_{2} \mathrm{PdCl}_{4}$ solution, the $\mathrm{Pd} / \mathrm{rGO} /$ PDA@QS synthesized in different concentrations of $\mathrm{K}_{2} \mathrm{PdCl}_{4}$ solution were measured by UV-visible spectroscopy. At first, the QS slices $(20 \mathrm{~mm} \times 10 \mathrm{~mm} \times 1 \mathrm{~mm})$ were ultrasonically cleaned by purified water, acetone, ethanol, and purified water in proper order to dislodge impurities and then dried them at $60{ }^{\circ} \mathrm{C}$. Subsequently, $0.5 \mathrm{~mol} \mathrm{~L}{ }^{-1} \mathrm{NaOH}$ solution was dropped into $20 \mathrm{mg} \mathrm{mL}^{-1}$ dopamine solution to adjust its $\mathrm{pH}$ to 8.5. The cleaned QS slices were immersed in the above-prepared dopamine solution for $2 \mathrm{~h}$ at room temperature and the PDA film was grown on the QS to obtain PDA@QS. Next, $0.5 \mathrm{mg} \mathrm{mL}^{-1}$ homogeneous GO suspension was obtained by ultrasonicated for $2.5 \mathrm{~h}$. The sample of PDA@QS was put in the $\mathrm{GO}$ suspension at $60{ }^{\circ} \mathrm{C}$ for $3 \mathrm{~h}$ to obtain the GO/PDA@QS. Then GO/PDA@QS was immersed in precursor $\mathrm{K}_{2} \mathrm{PdCl}_{4}$ solution with the existence of ascorbic acid $\left(0.1 \mathrm{~mol} \mathrm{~L}^{-1}\right)$ in water bath at $60^{\circ} \mathrm{C}$ for $80 \mathrm{~min}$ to

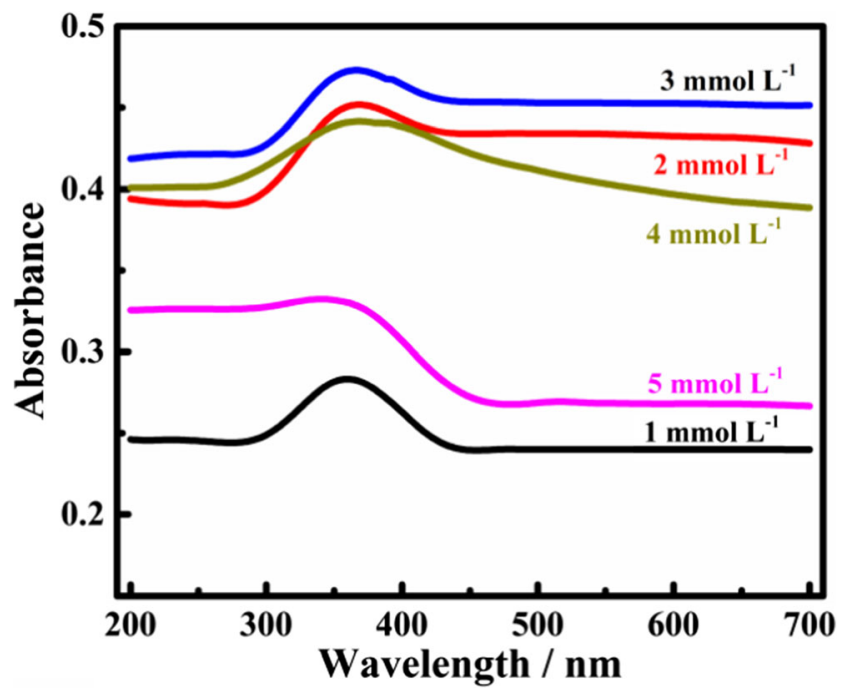

Fig. 1 The LSPR effect of the Pd/rGO/PDA@QS composites in different concentrations of $\mathrm{K}_{2} \mathrm{PdCl}_{4}$ solution. Lines 1, 2, 3, 4, and 5 corresponded to the spectra of Pd NPs in Pd/rGO/PDA@QS samples, which were obtained from different concentrations of $\mathrm{K} 2 \mathrm{PdCl} 4$ solution, respectively, $1 \mathrm{mmol} \mathrm{L}^{-1}, 2 \mathrm{mmol} \mathrm{L}^{-1}, 3 \mathrm{mmol} \mathrm{L}^{-1}, 4 \mathrm{mmol} \mathrm{L}^{-1}$, and $5 \mathrm{mmol} \mathrm{L}^{-1}$ obtain Pd/GO/PDA@QS. In addition, the concentration of precursor $\mathrm{K}_{2} \mathrm{PdCl}_{4}$ solution was $1 \mathrm{mmol} \mathrm{L}{ }^{-1}, 2 \mathrm{mmol} \mathrm{L}^{-1}$, $3 \mathrm{mmol} \mathrm{L}^{-1}, 4 \mathrm{mmol} \mathrm{L}^{-1}$, and $5 \mathrm{mmol} \mathrm{L}^{-1}$, respectively. At last, the above Pd/GO/PDA@QS samples were annealed for $2 \mathrm{~h}$ at $200{ }^{\circ} \mathrm{C}$ to obtain the $\mathrm{Pd} / \mathrm{rGO} / \mathrm{PDA} @ \mathrm{QS}$ composites.

\section{Synthesis of Pd/rGO/PDA@NF}

Pd/rGO/PDA@NF was synthesized by the similar method to analyze the electrocatalytic performance and stability of this composite material. The concentration of $\mathrm{K}_{2} \mathrm{PdCl}_{4}$ solution is $3 \mathrm{mmol} \mathrm{L}^{-1}$ from LSPR effect of Pd NPs in Pd/rGO/PDA@QS composite. The NF sheets $(20 \mathrm{~mm} \times 10 \mathrm{~mm} \times 1 \mathrm{~mm})$ were ultrasonically cleaned by purified water, acetone, ethanol, and purified water in proper order to remove the impurities, then dried at $60^{\circ} \mathrm{C}$. Thereafter, the synthesis process of PDA film on the NF surface (PDA@NF) was same as the fabrication procedure of $\mathrm{PDA} @ \mathrm{QS}$, only the QS substrate was changed to $\mathrm{NF}$ sheet. Then, the fabrication process of GO film on the surface of PDA@NF (GO/PDA@NF), Pd NPs on the surface of GO/PDA@NF composite (Pd/GO/PDA@NF), and Pd/ rGO/PDA@NF were also the same as the synthesis procedure of GO/PDA@QS,Pd/GO/PDA@QS, and Pd/rGO/PDA@QS, respectively, only the quartz slices were replaced to the nickel foam sheets. In addition, the composite of Pd NPs, PDA, and NF (Pd/PDA@NF) was synthesized by the similar method of Pd/rGO/PDA@NF, but without adding GO.

\section{Characterization}

LSPR spectra were recorded by UV-visible (Hitachi U-3310) with the detection range of $200 \sim 700 \mathrm{~nm}$. The morphologies and chemical elements of the asprepared composites were obtained by scanning electron microscope (SEM, S-4800, Hitachi, Japan) with an energy dispersive spectrometer (EDS) analysis. The morphology and lattice structures of composites surface were further characterized by a high-resolution transmission electron microscope (TEM, JEM-2100, Japan). Raman spectra were carried out by using a Micro Confocal Laser Raman Spectrometer and the source of radiation was $\mathrm{Ar}^{+}$laser with wavelength of $514.5 \mathrm{~nm}$. The structure and crystallization properties of the samples were characterized by the X-ray diffractometer (D8 ADVANCE, Bruker, Germany) with $\mathrm{Cu} \mathrm{K}_{\alpha}$ radiation $(\lambda=0.1542 \mathrm{~nm})$ at $40 \mathrm{kV}$ and $40 \mathrm{~mA}$ with a scan rate of $7^{\circ} \mathrm{min}^{-1}$. X-ray photoelectron spectroscopy (XPS) measurements were performed by Model PHI 5300 (USA) to analyze the valence and state of chemical elements. The loading of Pd on the electrocatalyst surface was detected by inductively coupled plasma-optical emission spectrometry (ICP-OES, iCAP6300, ThermoFisher). 

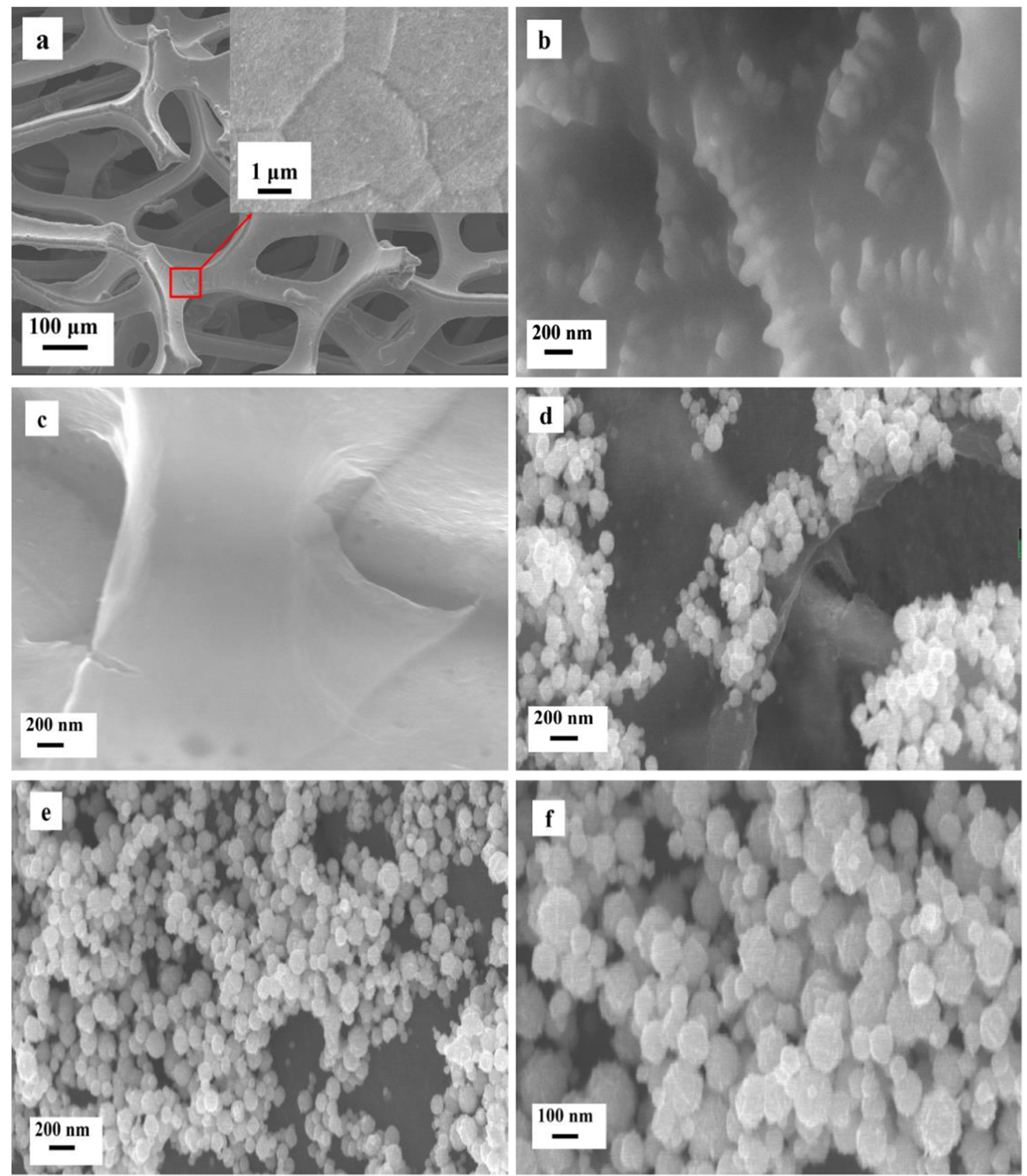

Fig. 2 SEM images of different composite surface: (a) NF, (b) PDA@NF, (c) GO/PDA@NF, (d) Pd/GO/PDA@NF, (e) and (f) Pd/rGO/PDA@NF

\section{Electrochemical Measurements}

The property of electrocatalyst was performed by the electrochemical workstation (CHI 760E, CH instruments, Shanghai) using a standard three electrodes in alkaline medium at room temperature. The counter electrode and reference electrode were platinum sheet $(2.0 \mathrm{~cm} \times 1.0 \mathrm{~cm})$ and saturated calomel electrode (SCE), respectively. The as-prepared composites were used directly as working electrodes. The cycle voltammetry $(\mathrm{CV})$ was measured by electrochemical workstation to assess the electrocatalytic performance of composites. The $\mathrm{KOH}$ solution was used as the electrolyte to provide conductive effect for ethanol electrochemical test. The potentially dissolved oxygen solution in electrolyte was removed by bubbling high purity $\mathrm{N}_{2}$ for 15 min before electrochemical measurements. The range of voltage potential was limited from 0.8 to $0.3 \mathrm{~V}$ (vs. SCE) of the CV performance and any CV curves were activated after 40 cycles for stabilization. 
Fig. 3 EDS images of (a) $\mathrm{Pd} / \mathrm{GO}$ / PDA@NF and (b) Pd/rGO/ PDA@NF
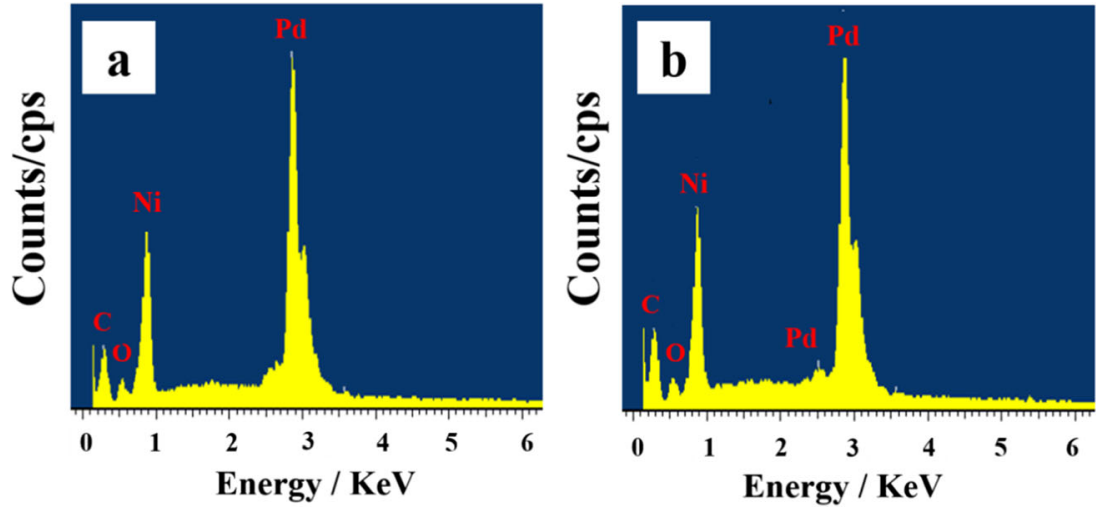

\section{Results and Discussion}

The electrocatalyst was synthesized by a combined chemical and annealing method. The Pd NPs as an effective component of electrocatalyst were obtained by precursor $\mathrm{K}_{2} \mathrm{PdCl}_{4}$, which was reduced by ascorbic acid. The rGO could provide large surface area to load Pd NPs for enhancing electrochemical activity of ethanol oxidation. The morphology and chemical composition of the composite material can be characterized by SEM, EDS, TEM, XRD, Raman spectra, XPS, and ICP-OES. Moreover, the LSPR effect and electrochemical measurement determined the optimal experimental conditions and the electrocatalytic activity or stability for ethanol oxidation, respectively.

\section{LSPR Effect}

The Pd NPs exhibited distinct LSPR absorption peaks at the range of $300 \sim 800 \mathrm{~nm}$ due to different concentrations of precursor $\mathrm{K}_{2} \mathrm{PdCl}_{4}$ solution [33]. In order to select the optimal concentration of precursor $\mathrm{K}_{2} \mathrm{PdCl}_{4}$ solution, the LSPR absorption peaks of $\mathrm{Pd} / \mathrm{rGO} / \mathrm{PDA} @ \mathrm{QS}$ were carried out to

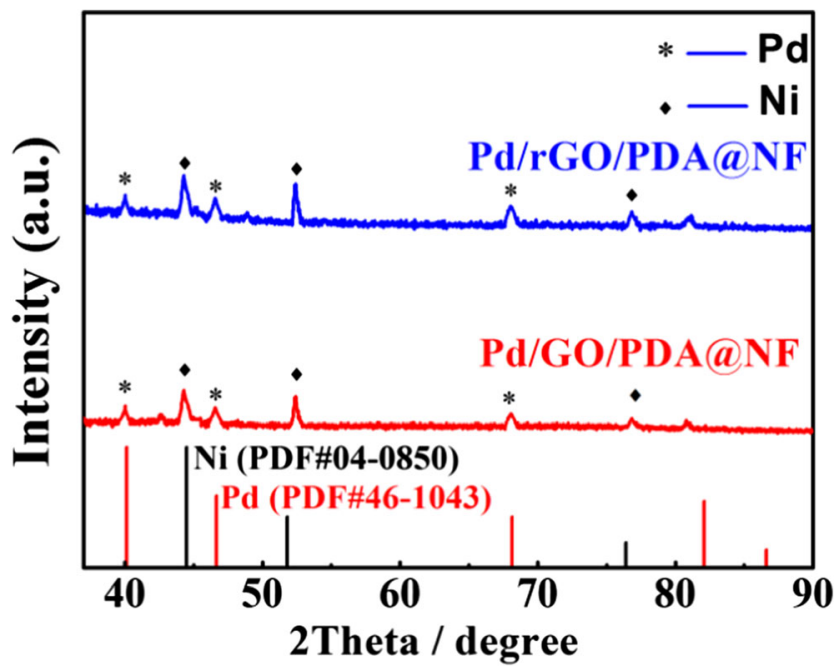

Fig. 4 XRD patterns of Pd/GO/PDA@NF and Pd/rGO/PDA@NF composites determine the absorption peak of Pd NPs. As shown in Fig. 1, the intensity of absorbance increased as the concentration of the precursor $\mathrm{K}_{2} \mathrm{PdCl}_{4}$ solution up to $3 \mathrm{mmol} \mathrm{L}^{-1}$, and then it gradually decreased with the concentration increasing to $5 \mathrm{mmol} \mathrm{L}^{-1}$. This also indicated that the absorbance peaks of Pd NPs were in the range of $340 \sim 370 \mathrm{~nm}$ and the strongest LSPR peak was attributed by line 3 , which was obtained from $3 \mathrm{mmol} \mathrm{L}^{-1} \mathrm{~K}_{2} \mathrm{PdCl}_{4}$ solution. Therefore, according to the LSPR effect of Pd NPs in the composites, the optimal concentration of $\mathrm{K}_{2} \mathrm{PdCl}_{4}$ solution was determined to be $3 \mathrm{mmol} \mathrm{L}^{-1}$.

\section{Morphology and Composition Analysis}

The synthesized composites were scanned by SEM to obtain the surface morphology. The SEM images of different composites were shown in Fig. 2, containing NF, PDA@NF, GO/ PDA@NF,Pd/GO/PDA@NF, and Pd/rGO/PDA@NF. In Fig. 2a, the three-dimensional NF sheet showed the numerous and average networks in the frame structure which provided the huge supporting base for rGO or Pd NPs. After immersing in PDA solution, it can be obviously observed that the PDA particles were uniformly distributed on the NF surface as shown in Fig. 2b, which could provide a certain amount of adherence points for the adsorption of GO. This also confirmed that the PDA was successfully adsorbed on the NF surface. Then, by comparing with Fig. $2 b$, it can be clearly seen that the GO-like wavy tulle was successfully deposited on the PDA@NF surface as shown in Fig. 2c. Moreover, the wrinkled GO can reduce the contact resistance and preserve the porous structure to support active points [31].

As can be seen from Fig. 2(d-f), the similar shape of spherical Pd NPs were successfully grown on the GO/PDA@NF surface in Pd/GO/PDA@NF and Pd/rGO/PDA@NF. The numerous spherical Pd NPs were dispersed on the GO film with the similar diameter of 30 to $200 \mathrm{~nm}$ in two composites. Compared with two samples (Fig. $2 \mathrm{~d}$ and 2e), it can be found that Pd NPs of Pd/rGO/PDA@NF (Fig. 2e) were grown more inseparable and combined with the substrate stronger than unannealed Pd NPs (Fig. 2d). And this phenomenon was more 
Fig. 5 TEM images of PDA (a), GO/PDA (b) and Pd/rGO/PDA (c), and HRTEM of Pd/rGO/PDA (d). The inset of $\mathbf{c}$ is the morphology of the small Pd NPs. The inset of $(\mathbf{d})$ is the SAED patterns of $\mathrm{Pd} / \mathrm{rGO} / \mathrm{PDA}$
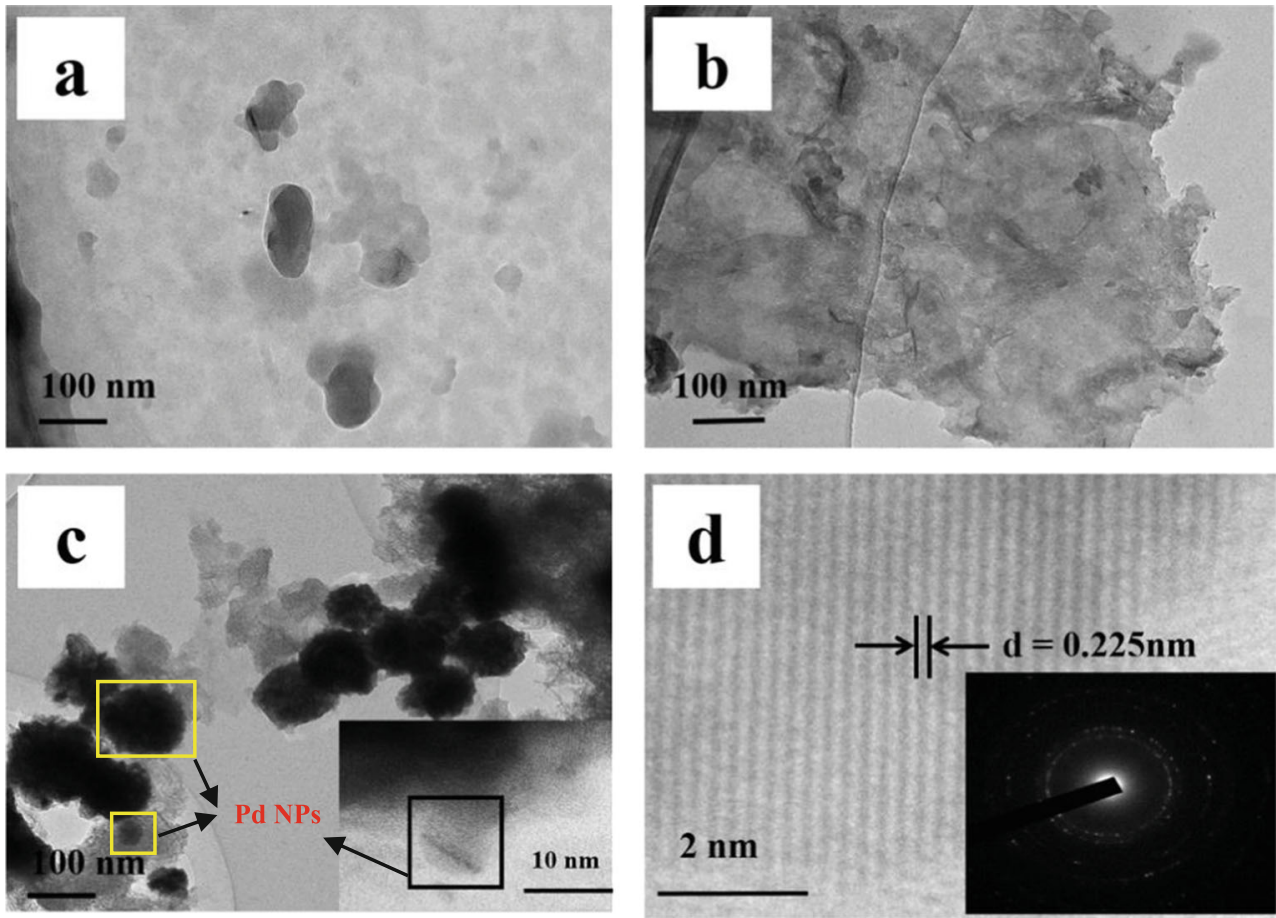

pronounced at higher magnifications of $\mathrm{Pd} / \mathrm{rGO} / \mathrm{PDA} @ \mathrm{NF}$ in Fig. 2f.

The chemical components of the Pd/GO/PDA@NF and Pd/rGO/PDA@NF composites were also determined by EDS spectra as shown in Fig. 3. The EDS spectra of $\mathrm{Pd} / \mathrm{GO} /$ PDA@NF and Pd/rGO/PDA@NF displayed the main dispersion of elements $\mathrm{Pd}$ and Ni on the surface, which confirmed that the Pd NPs were successfully deposited on the composite surface.

XRD measurement was carried out to further analyze the crystallization state and compositions of Pd/GO/PDA@NF and Pd/rGO/PDA@NF composites. As shown in Fig. 4, three diffraction peaks at $44.30^{\circ}, 52.42^{\circ}$, and $76.80^{\circ}$ were assigned to $\mathrm{Ni}(111), \mathrm{Ni}(200)$, and $\mathrm{Ni}(220)$ lattice planes of cubic nickel

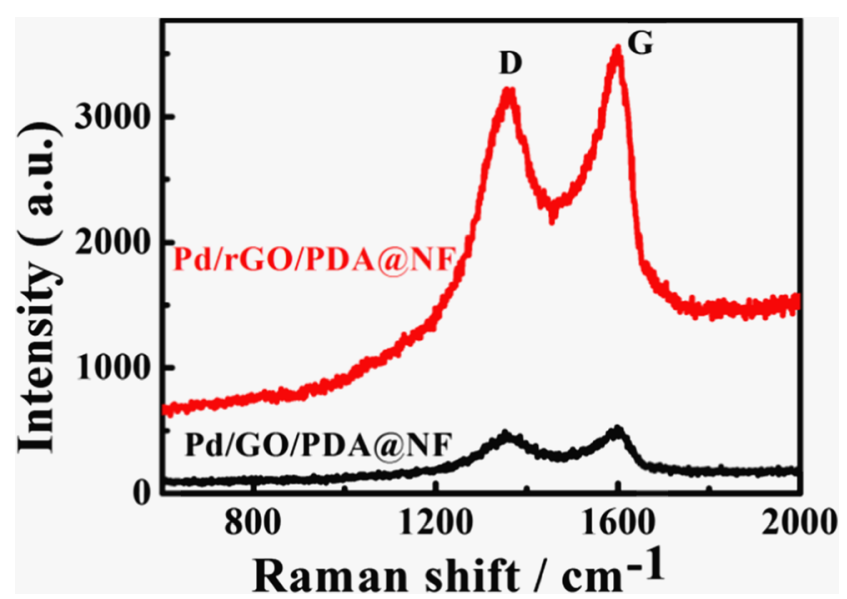

Fig. 6 Raman spectra of Pd/GO/PDA@NF and Pd/rGO/PDA@NF composites
(JCPDS 04-0850) in XRD curves of two composites. In addition, the standard diffraction peaks at $2 \theta=40.0^{\circ}, 46.6^{\circ}$, and $68.1^{\circ}$ corresponded to the (111), (200), and (220) lattice planes of cubic palladium (JCPDS 46-1043), respectively. So the similar peaks at $2 \theta=40.1^{\circ}, 46.7^{\circ}$, and $68.1^{\circ}$ in two curves of Fig. 4 were obtained, which corresponded well to the (111), (200), and (220) lattice planes of cubic Pd.

TEM analysis was measured to further investigate the surface morphology and crystal structural features of the composites in more detail by high-resolution transmission electron microscope (HRTEM) and selected area electronic diffraction (SAED). The TEM images in Fig. 5(a-c) displayed the morphologies of PDA, GO, and Pd NPs, consistent with SEM (Fig. 2) observations. Using the graphene as a support, large amounts of little spherical Pd NPs with a diameter of $8 \mathrm{~nm}$ aggregated into the relatively homogeneous spheres with average sizes of $100 \mathrm{~nm}$. These homogeneous spheres were anchored onto the GO sheet, as shown in Fig. $5 \mathrm{c}$ and the inset. The lattice fringes in Fig. $5 \mathrm{~d}$ were measured to be $0.225 \mathrm{~nm}$, and according to the Bragg's Law $2 d \sin \theta=\mathrm{n} \lambda$, where $d$ is the interplanar spacing of Pd NPs, $\theta$ is the diffraction angle between the incident $\mathrm{X}$-ray and the corresponding crystal plane, $n$ is the diffraction order $(n=1)$, and $\lambda$ is the $\mathrm{X}$-ray wavelength $(\lambda=0.1542 \mathrm{~nm})$. So we can obtain the value $2 \theta=40.1^{\circ}$, which can be assigned to cubic Pd (111) lattice planes. The SAED patterns (inset of Fig. 5d) contained several concentric diffraction rings of spots, suggesting that the spherical Pd NPs are polycrystalline state. In addition, the lattice fringe of Pd NPs was calculated from SAED patterns as $0.225 \mathrm{~nm}$, confirming the presence of cubic phase $\operatorname{Pd}(111)$ lattice planes. 
Fig. 7 (a) XPS full scan spectrum of different composites: $\mathrm{rGO} /$ PDA@NF,Pd/GO/PDA@NF, Pd/rGO/PDA@NF; (b) C 1s XPS core level spectra of $\mathrm{Pd} / \mathrm{GO} /$ PDA@NF composite; (c) C 1s XPS core level spectra of $\mathrm{Pd} / \mathrm{rGO}$ PDA@NF composite; (d) Ni 2p XPS core level spectra of $\mathrm{Pd} / \mathrm{GO} /$ PDA@NF composite; (e) Ni 2p XPS core level spectra of $\mathrm{Pd} / \mathrm{rGO} /$ PDA@NF composite; (f) Pd 3d XPS survey spectra of $\mathrm{Pd} / \mathrm{GO} /$ PDA@NF; (g) Pd 3d XPS survey spectra of Pd/rGO/PDA@NF
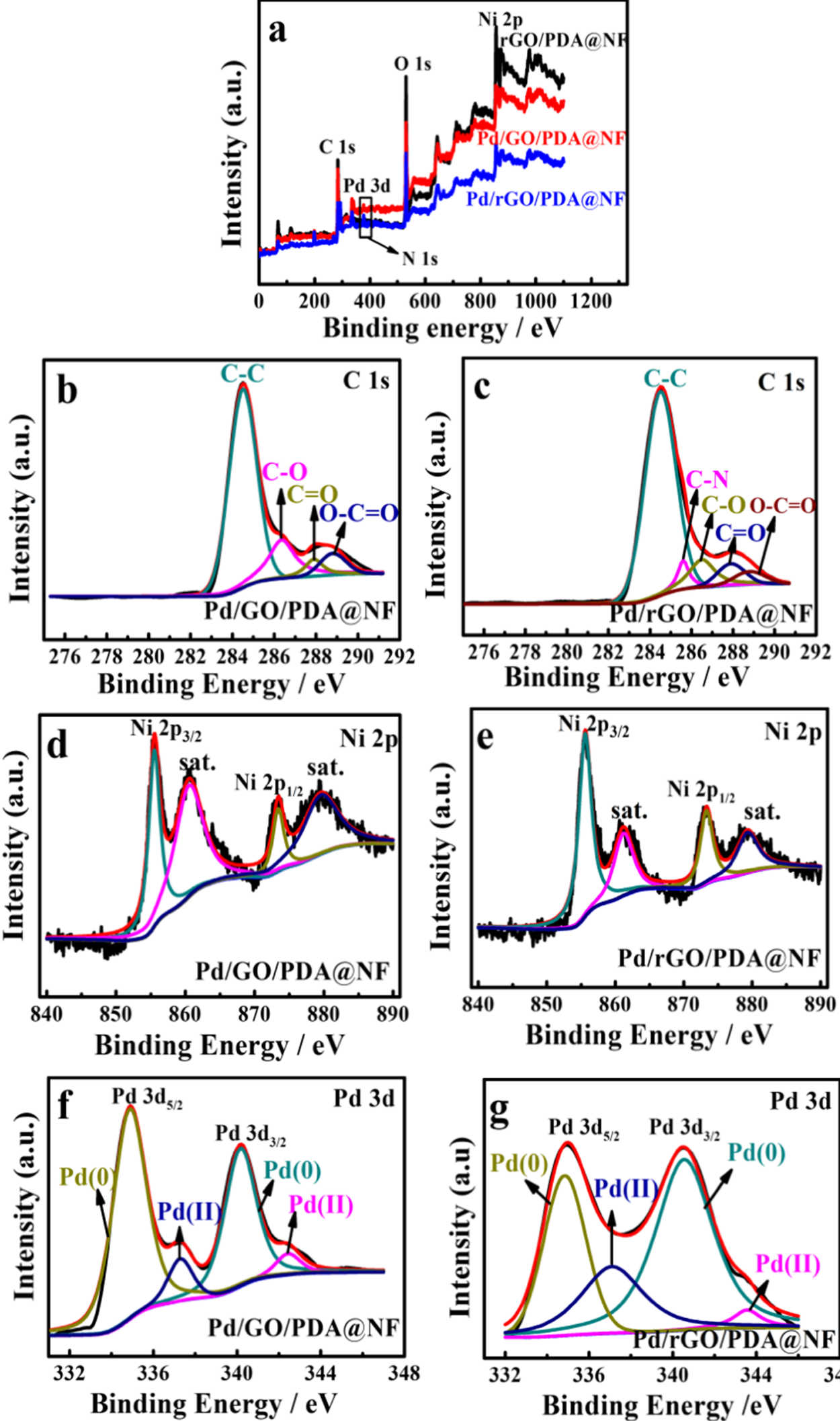

Raman spectra have become a widely used method to analyze and characterize the structural, double carbon-carbon bonds, and electron-phonon coupling in graphene [34, 35]. The peak at about $1600 \mathrm{~cm}^{-1}$ is $\mathrm{G}$ peak which results from 


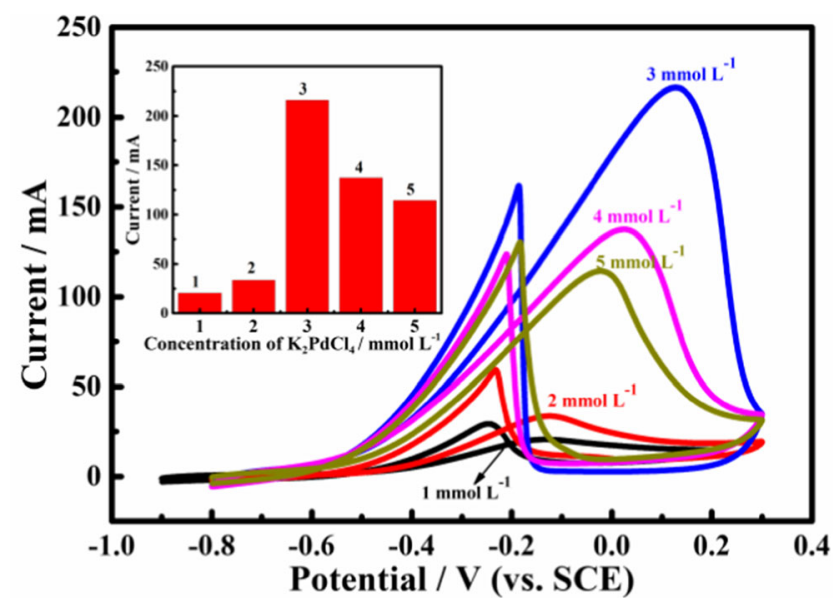

Fig. 8 The CV curves of Pd/rGO/PDA@NF in different concentrations of $\mathrm{K}_{2} \mathrm{PdCl}_{4}$ solution: $1 \mathrm{mmol} \mathrm{L}^{-1}, 2 \mathrm{mmol} \mathrm{L}^{-1}, 3 \mathrm{mmol} \mathrm{L}^{-1}, 4 \mathrm{mmol} \mathrm{L}^{-1}$, $5 \mathrm{mmol} \mathrm{L}^{-1}$. The inset is a plot of current density and concentration of $\mathrm{K}_{2} \mathrm{PdCl}_{4}$

first-order scattering of the $\mathrm{E}_{2 \mathrm{~g}}$ mode for $\mathrm{sp}^{2}$ carbon atoms [36]; while the other is D peak at around $1350 \mathrm{~cm}^{-1}$ which comes from the structural defects or grain boundaries of amorphous carbon species [36]. Therefore, the Raman spectra of Pd/GO/PDA@NF and Pd/rGO/PDA@NF composites were measured to prove that the $\mathrm{GO}$ was reduced to $\mathrm{rGO}$ after annealing. As can be seen in Fig. 6, the two characteristic peaks of Pd/GO/PDA@NF and Pd/rGO/PDA@NF composites corresponding to $\mathrm{G}$ peak and $\mathrm{D}$ peak at around $1600 \mathrm{~cm}^{-1}$ and $1351 \mathrm{~cm}^{-1}$ were obtained, respectively. Generally, the intensity ratio $\left(I_{\mathrm{D}} / I_{\mathrm{G}}\right)$ between D peak and G peak is associated with the density of defects and graphitization for graphenebased materials [37]. So we draw the conclusion in Fig. 6, the $I_{\mathrm{D}} / I_{\mathrm{G}}$ ratio of $\mathrm{Pd} / \mathrm{GO} / \mathrm{PDA} @ \mathrm{NF}(0.93)$ was higher than $\mathrm{Pd} /$ rGO/PDA@NF (0.89), indicating that the defects of GO were more than rGO. This confirmed that the GO had been reduced to $\mathrm{rGO}$ after annealed for high temperature.

Furthermore, the XPS measurement can give assistance to analyze compositions and structure to further supplement the information of the composites. The XPS spectra were used to characterize the composites to further confirm the chemical states of specific ingredients and demonstrate particle surface character of the composites. The XPS full scan spectrum of rGO/PDA@NF, Pd/GO/PDA@NF, and Pd/rGO/PDA@NF was determined in Fig. 7a, which mainly displayed the carbon, oxygen, nitrogen, palladium, and nickel species. For three composites, the peak located at $284 \mathrm{eV}$ and $530 \mathrm{eV}$ was ascribed to the characteristic peak of $\mathrm{C} 1 \mathrm{~s}$ and $\mathrm{O} 1 \mathrm{~s}$, respectively. The peak located at $400 \mathrm{eV}$ was attributed to the characteristic peak of $\mathrm{N} 1 \mathrm{~s}$, which showed that the PDA was successfully coated on the surface of NF sheet of all composites. In addition, the Pd $3 \mathrm{~d}$ peak at about $338 \mathrm{eV}$ was observed in the spectrum of Pd/GO/PDA@NF and Pd/rGO/PDA@NF by comparison in three composites, indicating that Pd NPs were deposited on the GO/PDA@NF surface.

In detail, as can be seen from the Fig. $7 \mathrm{~b}$, the $\mathrm{C} 1 \mathrm{~s}$ spectrum of Pd/GO/PDA@NF can be split into four peaks with binding energies at about $284.5 \mathrm{eV}, 286.4 \mathrm{eV}, 287.9 \mathrm{eV}$, and $288.8 \mathrm{eV}$, corresponding to $\mathrm{C}-\mathrm{C}, \mathrm{C}-\mathrm{O}, \mathrm{C}=\mathrm{O}$, and $\mathrm{O}-\mathrm{C}=\mathrm{O}$ species, respectively [38, 39]. In Fig. 7c, the $\mathrm{C} 1 \mathrm{~s}$ XPS spectrum of Pd/rGO/PDA@NF can be divided to five peaks with binding energies at about $284.5 \mathrm{eV}, 285.6 \mathrm{eV}, 286.4 \mathrm{eV}, 287.9 \mathrm{eV}$, and288.8 eV, which related to $\mathrm{C}-\mathrm{C}, \mathrm{C}-\mathrm{N}, \mathrm{C}-\mathrm{O}, \mathrm{C}=\mathrm{O}$, and $\mathrm{O}-$ $\mathrm{C}=\mathrm{O}$ species. By comparing Figs. $7 \mathrm{~b}$ and $\mathrm{c}$, it can be obviously shown that the existence of C-N bond at binding energy $285.6 \mathrm{eV}$ citified the presence of PDA on the surface of nickel foam in Pd/rGO/PDA@NF and demonstrated a little amount of $\mathrm{N}$ element from PDA layer was doped in the rGO.

The XPS spectrum of Ni 2p peak in Fig. $7 \mathrm{~d}$ and e indicated the chemical states of the nickel substrate. In Fig. 7d, the two main peaks of binding energy of $\mathrm{Ni} 2 \mathrm{p}_{3 / 2}$ and $\mathrm{Ni} 2 \mathrm{p}_{1 / 2}$ at $855.7 \mathrm{eV}$ and $873.3 \mathrm{eV}$ with two satellite peaks, respectively, which revealed the oxidation state of $\mathrm{Ni}^{2+}$ [40]. Compared with Fig. $7 e$, the height of satellite peak of $\mathrm{Ni} 2 \mathrm{p}_{3 / 2}$ and $\mathrm{Ni}$ $2 p_{1 / 2}$ were smaller than their own, the intensity of $\mathrm{Ni} 2 \mathrm{p}$ peak in the surface of $\mathrm{Pd} / \mathrm{rGO} / \mathrm{PDA} @ \mathrm{NF}$ significantly decreased due to being annealed at high temperature. Annealing can eliminate the internal stress, reduce the high hardness, and enhance the interactions of Pd NPs, GO, PDA, and NF. The main difference between images Fig. $7 \mathrm{~d}$ and e of $\mathrm{Pd} / \mathrm{GO} /$ PDA@NF and Pd/rGO/PDA@NF is also from the annealed process. The XPS spectrum of $\mathrm{Pd} 3 \mathrm{~d}$ peak for $\mathrm{Pd} / \mathrm{GO} /$
Fig. 9 The $\mathrm{CV}$ curves of $\mathrm{Pd} / \mathrm{rGO}$ / PDA@NF, Pd/GO/PDA@NF, Pd/PDA@NF and rGO/ PDA@NF in (a) $1 \mathrm{~mol} \mathrm{~L}^{-1} \mathrm{KOH}$ solution; (b) $1 \mathrm{~mol} \mathrm{~L}^{-1} \mathrm{KOH}$ electrolyte containing $1 \mathrm{~mol} \mathrm{~L}^{-1}$ ethanol at $100 \mathrm{mV} \mathrm{s}^{-1}$
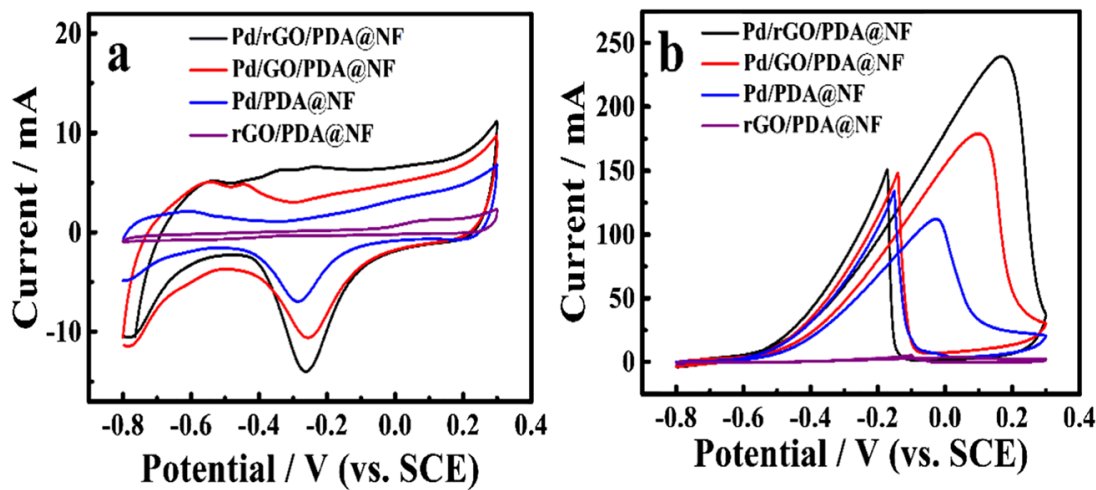


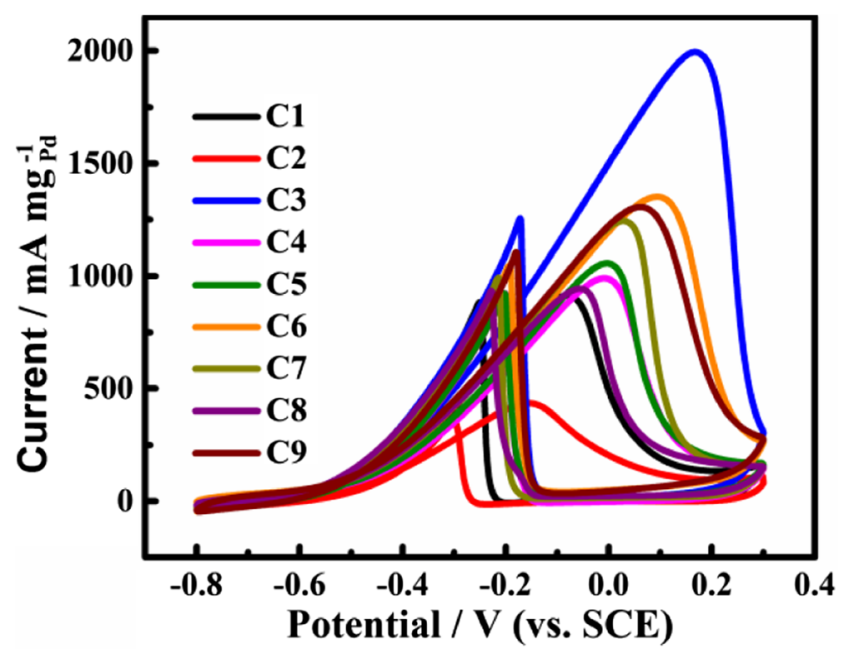

Fig. 10 The $\mathrm{CV}$ curves of $\mathrm{Pd} / \mathrm{rGO} / \mathrm{PDA} @ \mathrm{NF}$ synthesized by different conditions $\mathrm{C} 1, \mathrm{C} 2, \mathrm{C} 3, \mathrm{C} 4, \mathrm{C} 5, \mathrm{C} 6, \mathrm{C} 7, \mathrm{C} 8$, and $\mathrm{C} 9$ in the solution containing $1 \mathrm{~mol} \mathrm{~L}^{-1} \mathrm{KOH}$ and $1 \mathrm{~mol} \mathrm{~L}^{-1}$ ethanol at $100 \mathrm{mV} \mathrm{s}^{-1}$, respectively

PDA@NF in Fig. 7f presented two main peaks of binding

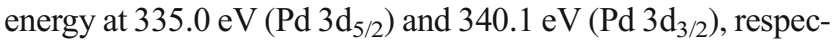
tively, which displayed the presence of $\mathrm{Pd}(0)$ [41] and the weaker couple of $336.9 \mathrm{eV}\left(\mathrm{Pd}_{3} \mathrm{~d}_{5 / 2}\right)$ and $342.4 \mathrm{eV}\left(\mathrm{Pd} 3 \mathrm{~d}_{3 / 2}\right)$ corresponded to Pd (II) [41]. In comparison with Fig. 7f, the Pd 3d binding energies of Pd/rGO/PDA@NF were slightly shifted for higher values than Pd/GO/PDA@NF composite. The shift of binding energies of Pd $3 \mathrm{~d}$ core level could modify the electronic structure and reflect the change of d-band center relative Fermi level $[42,43]$.

\section{Electrochemical Performance of As-prepared Electrodes}

The crucial factors in assessing performance of electrocatalyst include tolerance to the carbonaceous species and catalytic activity. The cycle voltammetry (CV) was measured to determine the electrochemical properties of those electrocatalysts or electrodes.

Figure 8 presented CV curves of $\mathrm{Pd} / \mathrm{rGO} / \mathrm{PDA} @ \mathrm{NF}$ fabricated in different concentrations of $\mathrm{K}_{2} \mathrm{PdCl}_{4}$ solution. The fabrication of Pd/rGO/PDA@NF composite in $3 \mathrm{mmol} \mathrm{L}^{-1}$ $\mathrm{K}_{2} \mathrm{PdCl}_{4}$ solution exhibited the maximum current value. And the inset of Fig. 8 showed the significant relationship between current and concentration of $\mathrm{K}_{2} \mathrm{PdCl}_{4}$ solution. The best electrocatalytic performance in EOR was consistent

Table 1 The $I_{\mathrm{f}} / I_{\mathrm{b}}$ of $\mathrm{Pd} / \mathrm{rGO} / \mathrm{PDA} @ \mathrm{NF}$ synthesized by different operation conditions

\begin{tabular}{llllllllll}
\hline Samples & C1 & C2 & C3 & C4 & C5 & C6 & C7 & C8 & C9 \\
\hline$I_{\mathrm{f}} / I_{\mathrm{b}}$ & 1.04 & 1.22 & 1.59 & 1.07 & 1.15 & 1.29 & 1.26 & 1.01 & 1.19 \\
\hline
\end{tabular}

with the strongest LSPR effect. So Pd/rGO/PDA@NF fabricated in $3 \mathrm{mmol} \mathrm{L}^{-1} \mathrm{~K}_{2} \mathrm{PdCl}_{4}$ solution was selected to determine the electrochemical behavior in EOR.

Figure 9a showed the CV curves of Pd/rGO/PDA@NF, Pd/GO/PDA@NF,Pd/PDA@NF, and rGO/PDA@NF in the potential range of -0.8 to $0.3 \mathrm{~V}$ (vs. SCE) at a scan rate of $100 \mathrm{mV} \mathrm{s}^{-1}$ in $1 \mathrm{~mol} \mathrm{~L}^{-1} \mathrm{KOH}$ solution. The $\mathrm{CV}$ profile of rGO/PDA@NF is essentially featureless in the potential range of -0.8 to $0.3 \mathrm{~V}$, which may be caused by interference from the PDA and graphene [18]. The CV curves of Pd/rGO/PDA@NF, Pd/GO/PDA@NF, and Pd/ PDA@NF displayed the similar appearance with the reduction peak of $\mathrm{PdO}$ at the potential range of -0.3 to $-0.2 \mathrm{~V}$ (vs. SCE). Another CV curve of rGO/PDA@ NF showed the gentle trend and not contained the reduction peak of PdO. As shown in Fig. 9b, the $\mathrm{CV}$ curves of $\mathrm{Pd} /$ rGO/PDA@NF,Pd/GO/PDA@NF, Pd/PDA@NF, and rGO/PDA@NF electrodes in the solution containing $1 \mathrm{~mol} \mathrm{~L}^{-1} \mathrm{KOH}$ and $1 \mathrm{~mol} \mathrm{~L}^{-1}$ ethanol at a scan rate of $100 \mathrm{mV} \mathrm{s}^{-1}$ were observed. Two oxidation peaks different from Fig. 9a can be obviously depicted in $\mathrm{Pd} / \mathrm{rGO} /$ PDA@NF, Pd/GO/PDA@NF, and Pd/PDA@NF, which confirmed the electrocatalytic activity of these asprepared composites in a solution of $1 \mathrm{~mol} \mathrm{~L}^{-1} \mathrm{KOH}$ and $1 \mathrm{~mol} \mathrm{~L}^{-1}$ ethanol. However, the ethanol oxidation peak of rGO/PDA@NF in the electrolyte was hardly observed, indicating the absence of electrochemical activity. In addition, the peak current intensity of Pd/rGO/PDA@NF was higher than Pd/GO/PDA@NF and Pd/PDA@NF obviously, which displayed the better electrocatalytic performance of Pd/rGO/PDA@NF for ethanol oxidation. The presence of $\mathrm{rGO}$ can enhance the electrochemical activity toward ethanol electrocatalysis by comparing Pd/rGO/PDA@NF and Pd/PDA@NF.

The reverse scan peak of $\mathrm{CV}$ curves in EOR is related to the intermediates of ethanol and these reaction intermediates will result in low activity of catalyst, which can be named "catalyst poisoning" [41]. Generally, a ratio of forward scan peak current intensity $\left(I_{\mathrm{f}}\right)$ to reverse scan peak current intensity $\left(I_{\mathrm{b}}\right)$ for $\mathrm{CV}$ curves can evaluate the tolerance limit and catalytic activity of the catalysts to intermediate carbonaceous species [42, 44]. To select the optimal experimental conditions for the excellent ethanol electrocatalytic performance, the orthogonal test of four factors at three different levels was carried out in Table S1 (Supplementary material).

We synthesized Pd/rGO/PDA@NF composites in nine conditions and named them $\mathrm{C} 1, \mathrm{C} 2, \mathrm{C} 3, \mathrm{C} 4, \mathrm{C} 5, \mathrm{C} 6, \mathrm{C} 7$, $\mathrm{C} 8$, and $\mathrm{C} 9$.

The CV curves of Pd/rGO/PDA@NF for different conditions were measured in the aqueous solution of $1 \mathrm{~mol} \mathrm{~L}^{-1}$ $\mathrm{KOH}$ and $1 \mathrm{~mol} \mathrm{~L}^{-1}$ ethanol at $100 \mathrm{mV} \mathrm{s}^{-1}$ as shown in Fig. 10. There are two apparent oxidation peaks: one peak at -0.1 to $0.15 \mathrm{~V}$ appears during forward scan and comes from 
Fig. 11 (a) The CV curves of $\mathrm{Pd}$ rGO/PDA@NF from the first to the 400th cycle in the solution of $1 \mathrm{~mol} \mathrm{~L}-1$ KOH and $1 \mathrm{~mol} \mathrm{~L}^{-1}$ ethanol at a scan rate of $100 \mathrm{mV} \mathrm{s}^{-1}$; (b) The current intensity of forward scan peak vs. cycle number plot. $\mathrm{Pd} / \mathrm{rGO} /$ PDA@NF was synthesized by C3 in Table $\mathrm{S} 1$
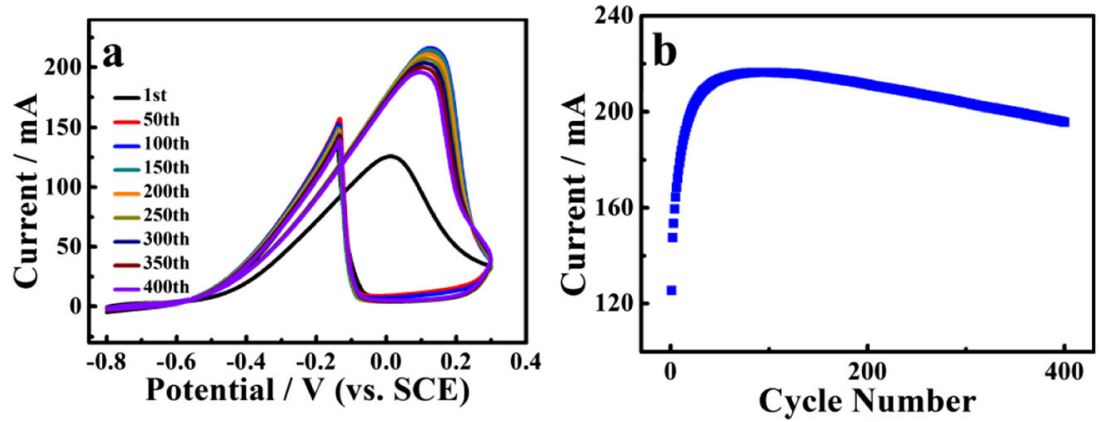

ethanol oxidation peak; the other peak at -0.25 to $-0.15 \mathrm{~V}$ occurs in reverse scan and results from the oxidation reaction of carbonaceous species. Additionally, the values of $I_{\mathrm{f}} / I_{\mathrm{b}}$ were summarized in Table 1. The Pd/rGO/PDA@NF $\left(I_{\mathrm{f}} / I_{\mathrm{b}}=1.59\right)$ was synthesized by $\mathrm{C} 3$ in Table $\mathrm{S} 1$, which was higher than others. This result indicated that Pd/rGO/PDA@NF synthesized in $\mathrm{C} 3$ has excellent tolerance to carbonaceous intermediates and higher ethanol catalytic performance than others. So, we next selected C3 to synthesize Pd/rGO/PDA@NF for all of ethanol oxidation tests. In addition, the electrochemical active surface area (ECSA) of electrocatalysts is other important parameter to evaluate the electrochemical activity. The ECSA was calculated by this equation: [45]

$E C S A=\frac{Q}{m \times C}$

where $\mathrm{Q}$ is the charge associated with the reduction of $\mathrm{PdO}$ on the surface $(\mathrm{mC}), \mathrm{m}$ is the mass of metallic $\mathrm{Pd}(\mathrm{mg})$, and $\mathrm{C}$ is the reduction charge density for $\mathrm{PdO}$ monolayer $(0.405 \mathrm{mC} /$ $\mathrm{cm}^{2}$ ). The ECSA of Pd/rGO/PDA@NF was calculated to be $19.08 \mathrm{~m}^{2} \mathrm{~g}^{-1}$ by this equation.

The poisoning effect against carbonaceous intermediates is associated to the ethoxi species $\left(\mathrm{CH}_{3} \mathrm{CO}_{\text {ads }}\right)$ and the hydroxyl species $\left(\mathrm{OH}_{\mathrm{ads}}\right)$ on the catalyst surface in electrolyte. The possible mechanism between $\mathrm{CH}_{3} \mathrm{CO}_{\text {ads }}$ and $\mathrm{OH}_{\text {ads }}$ on $\mathrm{Pd}$-based electrocatalyst toward ethanol oxidation can be depicted as following steps [46, 47]:

$\mathrm{Pd}+\mathrm{OH}^{-} \rightleftharpoons \mathrm{Pd}-\mathrm{OH}_{\mathrm{ads}}+\mathrm{e}^{-}$

$$
\begin{aligned}
& \mathrm{Pd}+\mathrm{CH}_{3} \mathrm{CH}_{2} \mathrm{OH} \rightleftharpoons \mathrm{Pd}-\left(\mathrm{CH}_{3} \mathrm{CH}_{2} \mathrm{OH}\right)_{\mathrm{ads}} \\
& \mathrm{Pd}-\left(\mathrm{CH}_{3} \mathrm{CH}_{2} \mathrm{OH}\right)_{\mathrm{ads}}+3 \mathrm{OH}^{-1} \rightarrow \mathrm{Pd}-\left(\mathrm{CH}_{3} \mathrm{CO}\right)_{\mathrm{ads}} \\
& \quad+3 \mathrm{H}_{2} \mathrm{O}+3 \mathrm{e}^{-} \\
& \mathrm{Pd}-\left(\mathrm{CH}_{3} \mathrm{CO}\right)_{\mathrm{ads}}+\mathrm{Pd}-\mathrm{OH}_{\mathrm{ads}} \rightarrow \mathrm{Pd}-\mathrm{CH}_{3} \mathrm{COOH}+\mathrm{Pd} \\
& \mathrm{Pd}-\mathrm{CH}_{3} \mathrm{COOH}+\mathrm{OH}^{-1} \rightarrow \mathrm{Pd}+\mathrm{CH}_{3} \mathrm{COO}^{-}+\mathrm{H}_{2} \mathrm{O}
\end{aligned}
$$

Meanwhile, the electrocatalytic stability of catalysts was an important evaluation standard for ethanol oxidation. The stability of catalyst toward ethanol oxidation was measured by the CV curves with multiple cycles. As shown in Fig. 11a, the $\mathrm{CV}$ curves of $\mathrm{Pd} / \mathrm{rGO} / \mathrm{PDA} @ \mathrm{NF}$ displayed a trend that the current intensity of forward and reverse scan peaks increased gradually before the 100th cycle and then declined after achieving the highest value of the current intensity. In detail, the current intensity of positive and negative scan peaks at the first cycle increased from $125.7 \mathrm{~mA}$ and $146.9 \mathrm{~mA}$ to $216.2 \mathrm{~mA}$ and $153.3 \mathrm{~mA}$ in the 100th cycle. This is indicative of overall increase of the current intensity of $\mathrm{Pd}$ most likely via increase of active surface areas of rGO from the first - 100th cycle [17]. Then the current intensity at both forward and reverse scan peaks gradually reduced from the 100th to the 400th and they were observed $195.7 \mathrm{~mA}$ and $138.7 \mathrm{~mA}$ in the 400th cycle. This is indicative of overall loss of the current intensity of Pd most likely via detachment and electrodissolution of $\mathrm{Pt}$ particles and poisoning to carbonaceous intermediates species from the 100th to the 400th cycle [18]. In addition, the value of peak potential increased in the cycle process. The reason of shift in peak potential may be the
Fig. 12 (a) The CV curves of $\mathrm{Pd} /$ rGO/PDA@NF in the solution of $1 \mathrm{~mol} \mathrm{~L}^{-1} \mathrm{KOH}$ and $1 \mathrm{~mol} \mathrm{~L}^{-1}$ ethanol at different scan rates of $5 \mathrm{mV} \mathrm{s}^{-1}, 25 \mathrm{mV} \mathrm{s}^{-1}, 50 \mathrm{mV} \mathrm{s}^{-1}$, $100 \mathrm{mV} \mathrm{s}^{-1}, 150 \mathrm{mV} \mathrm{s}^{-1}$, and $200 \mathrm{mV} \mathrm{s}^{-1}$. (b) The graph of current intensity vs. square roots of scan rate.Pd/rGO/PDA@NF was synthesized by $\mathrm{C} 3$ in Table S1
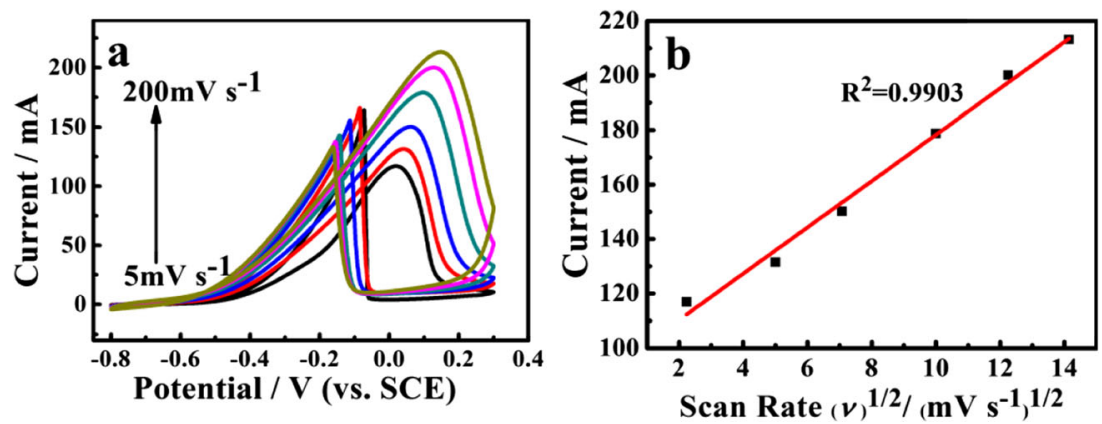
Fig. 13 (a) $\mathrm{CV}$ plots of $\mathrm{Pd} / \mathrm{rGO} /$ PDA@NF in the solution of $1 \mathrm{~mol} \mathrm{~L}^{-1} \mathrm{KOH}$ and different concentrations of ethanol $(\mathbf{a}-\mathbf{e})$ : $0.10,0.50,1.00,1.25$, and $1.50 \mathrm{~mol} \mathrm{~L}^{-1}$; (b) the plot of current intensity vs. concentration of ethanol solution. $\mathrm{Pd} / \mathrm{rGO} /$ PDA@NF was synthesized by C3 in Table $\mathrm{S} 1$
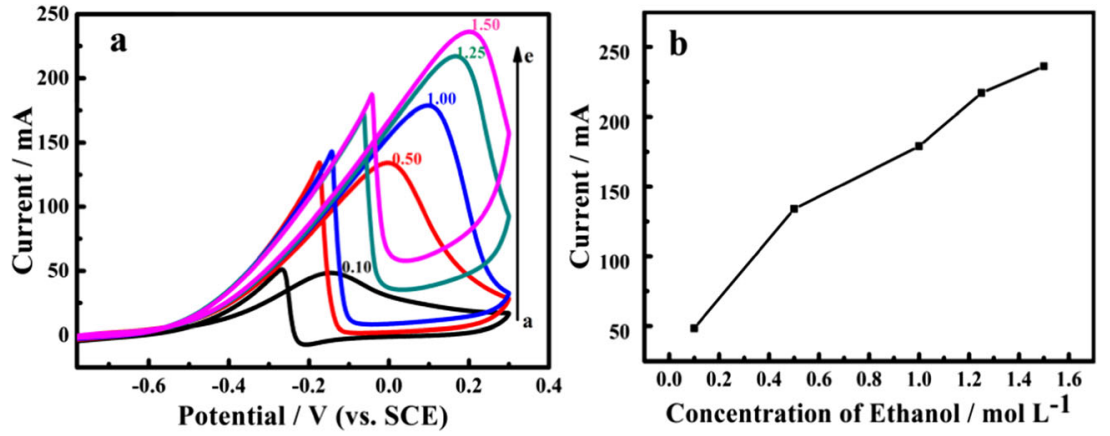

continuous production of carbon intermediates during the reaction.

As shown in Fig. 11b, the stability of Pd/rGO/PDA@NF was performed by current intensity of forward scan peak vs. cycle number to evaluate the long-term cycle stability directly of this catalyst toward ethanol oxidation. More evidently, the current intensity of forward scan peak gradually increased from the first cycle, then achieved the top point $(216.2 \mathrm{~mA})$. Next, the current intensity showed a slow decline in the cyclic process which meant the decreasing of the electrocatalytic performance for Pd/rGO/PDA@NF. It was found that the current intensity remained a stable decrease trend and kept $90.6 \%$ of the maximum value after 400 cycles. During the cyclic process, it showed that Pd/rGO/PDA@NF possessed a superior long-term stability.

The CV curves of Pd/rGO/PDA@NF toward ethanol oxidation in $1 \mathrm{~mol} \mathrm{~L}^{-1} \mathrm{KOH}$ solution containing $1 \mathrm{~mol} \mathrm{~L}^{-1}$ ethanol solution at different scan rates were shown in Fig. 12a. Evidently, the current intensity of forward and reverse scan peaks increased with the addition of scan rates in the same electrolyte. So Pd/rGO/PDA@NF exhibited great electrocatalytic performance with the increasing of scan rates for ethanol oxidation. As shown in Fig. 12b, the relationship between the current intensity of forward scan peak and square roots of scan rate was obviously linear $\left(\mathrm{R}^{2}=0.9903\right)$. This indicated that the ethanol electrocatalysis on Pd/rGO/PDA@NF was a diffusion-controlled process.

The concentration of ethanol or $\mathrm{KOH}$ solution also affects the catalytic activity toward ethanol oxidation. The current intensity of forward and reverse scan peak can change gradually with the variable concentration of the electrolyte.

The CV curves were measured in existence of different concentrations of ethanol (a-e) with $1 \mathrm{~mol} \mathrm{~L}^{-1} \mathrm{KOH}$ solution at scan rate of $100 \mathrm{mV} \mathrm{s}^{-1}$ in Fig. 13a. The current intensity of forward and reverse scan peaks gradually raised with the increase of ethanol concentration. Furthermore, the current intensity added obviously with an increase of ethanol concentration in Fig. 13b, which clearly displayed the excellent electrocatalytic performance for ethanol catalytic oxidation with the increasing of ethanol concentration.

The Fig. 14a showed the CV curves in the solution of $1 \mathrm{~mol} \mathrm{~L}^{-1}$ ethanol and different concentrations of $\mathrm{KOH}$ (ae) at a scan rate of $100 \mathrm{mV} \mathrm{s}^{-1}$. The current intensity of forward and reverse scan peaks increased with addition of $\mathrm{KOH}$ concentration. Figure $14 \mathrm{~b}$ obviously showed the increasing trend of current intensity with different concentrations of KOH solution. Additionally, the Pd/rGO/PDA@NF did not have obvious catalytic activity when the concentration of $\mathrm{KOH}$ solution was $0.10 \mathrm{~mol} \mathrm{~L}^{-1}$. So $\mathrm{KOH}$ electrolyte provides conductive effect in ethanol eletrocatalytic oxidation [40]. The catalytic activity of Pd/rGO/PDA@NF enhanced during frequent potential cycling change in the electrolyte with higher concentrations of $\mathrm{KOH}$ or ethanol in Figs. 13 and 14.

The catalytic parameters of Pd/rGO/PDA@NF catalyst and the electrochemical measurement results obtained from previously reported literatures are compared in Table 2, including the comparison of the peak potential, $\mathrm{I}_{\mathrm{f}} / \mathrm{I}_{\mathrm{b}}$ and ECSA of catalysts containing Pd NPs or rGO. In
Fig. 14 (a) $\mathrm{CV}$ curves of $\mathrm{Pd} / \mathrm{rGO} /$ PDA@NF in the solution of $1 \mathrm{~mol} \mathrm{~L}^{-1}$ ethanol and different concentrations of $\mathrm{KOH}(\mathbf{a}-\mathbf{e})$ : $0.10,0.75,1.00,1.50$, and $2.00 \mathrm{~mol} \mathrm{~L}^{-1}$; (b) the plot of current intensity vs. concentration of $\mathrm{KOH}$ solution. $\mathrm{Pd} / \mathrm{rGO} /$ PDA@NF was synthesized by C3 in Table S1
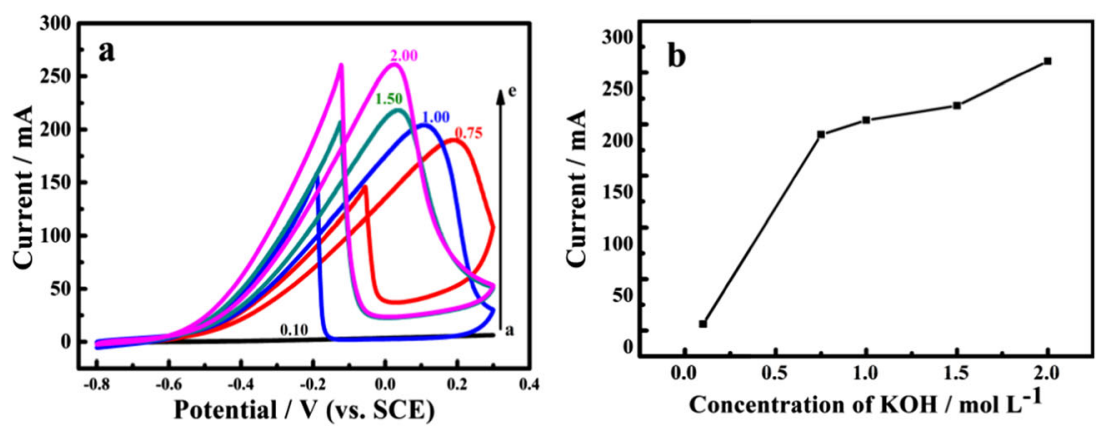
Table 2 Summary of literature catalytic parameters in ethanol oxidation of various Pd-based electrocatalysts

\begin{tabular}{lllcc}
\hline Electrode & Peak potential $(\mathrm{V})$ & $I_{\mathrm{f}} / I_{\mathrm{b}}$ & ECSA $\left(\mathrm{m}^{2} \mathrm{~g}^{-1}\right)$ & Reference \\
\hline $\mathrm{Pd} / \mathrm{RGO} / \mathrm{GC}$ & $-0.28^{\mathrm{a}}$ (vs. SCE) & $0.90^{\mathrm{a}}$ & 21.80 & {$[16]$} \\
$\mathrm{Pd} @ \mathrm{CoP} N S s / \mathrm{CFC}$ & $-0.25^{\mathrm{a}}$ (vs. SCE) & $1.04^{\mathrm{a}}$ & 40.30 & {$[45]$} \\
$\mathrm{Pt}-\mathrm{Pd}(1: 3) / \mathrm{RGO} / \mathrm{GC}$ & $-0.29^{\mathrm{a}}$ (vs. SCE) & $1.17^{\mathrm{a}}$ & - & {$[48]$} \\
$\mathrm{Pd} / \mathrm{GN} / \mathrm{GC}$ & $-0.27^{\mathrm{a}}$ (vs. SCE) & $1.08^{\mathrm{a}}$ & 24.6 & {$[49]$} \\
$\mathrm{Pd} / \mathrm{rGO} / \mathrm{PDA} @ \mathrm{NF}$ & 0.1 (vs. SCE) & 1.59 & 19.08 & This work \\
\hline
\end{tabular}

${ }^{\mathrm{a}}$ The value was evaluated from $\mathrm{CV}$ curves in the literatures this table, Pd/rGO/PDA@NF holds a higher value of $\mathrm{I}_{\mathrm{f}} / \mathrm{I}_{\mathrm{b}}$ and similar ECSA value. The excellent performance of Pd/rGO/PDA@NF for ethanol oxidation can attribute to NF, rGO, and Pd NPs. Firstly, NF can provide the large surface area for substance deposited. Secondly, the rGO can supply large surface area and good conductivity. Layered rGO existed abundant active sites to support more Pd NPs. The Pd NPs will be dispersed uniformly on the surface of $\mathrm{rGO}$, and reduced the agglomeration of Pd NPs. The good electrical conductivity of rGO and the excellent activity of Pd can be able to act synergistically together in ethanol electrocatalysis. At last, Pd NPs exhibited great electrocatalytic performance of anti-poisoning to carbonaceous intermediates and stability toward ethanol catalytic test.

\section{Conclusions}

The composite material of Pd nanoparticles, graphene, and polydopamine based on three-dimensional nickel foam substrate was successfully synthesized for ethanol oxidation. Pd nanoparticles were obtained via reduction of precursor $\mathrm{K}_{2} \mathrm{PdCl}_{4}$ using ascorbic acid at $60{ }^{\circ} \mathrm{C}$ for $80 \mathrm{~min}$. Localized surface plasmon resonance was performed to determine the optimal synthesized condition by absorbance peak to obtain Pd nanoparticles. The nickel foam substrate provided a considerable support structure, which brought a large surface area for supporting polydopamine, graphene, and Pd nanoparticles. Moreover, polydopamine as a binder combined nickel foam with graphene closer. The Pd nanoparticles acted as an effective ingredient of electrocatalyst and graphene existed large surface area and could supply large amounts of active sites for nanoparticles toward ethanol oxidation. The higher ratio of forward scan to reverse scan peak current intensity $\left(I_{\mathrm{f}} / I_{\mathrm{b}}=1.59\right)$ was observed through the analysis of electrochemical test, suggesting that the composite material exhibited a higher tolerance of against poisoning to carbonaceous intermediate species and excellent catalytic activity. In addition, the peak current intensity of forward scan peak retained $90.6 \%$ of maximum value after 400 cycles, which powerfully demonstrated the great stability of the composite material. The excellent electrocatalyst can be obtained by this synthesized method, which could be used as a promising electrochemical catalyst material toward ethanol oxidation for fuel cell.

Funding Information We gratefully acknowledge the National Natural Science Foundation of China (No. 21271027) for their support of this work.

Open Access This article is licensed under a Creative Commons Attribution 4.0 International License, which permits use, sharing, adaptation, distribution and reproduction in any medium or format, as long as you give appropriate credit to the original author(s) and the source, provide a link to the Creative Commons licence, and indicate if changes were made. The images or other third party material in this article are included in the article's Creative Commons licence, unless indicated otherwise in a credit line to the material. If material is not included in the article's Creative Commons licence and your intended use is not permitted by statutory regulation or exceeds the permitted use, you will need to obtain permission directly from the copyright holder. To view a copy of this licence, visit http://creativecommons.org/licenses/by/4.0/.

\section{References}

1. Y. Oh, J. Kang, S. Nam, S. Byun, B. Park, Pt/AlPO 4 nanocomposite thin-film electrodes for ethanol electrooxidation. Mater. Chem. Phys. 135(1), 188-192 (2012)

2. J. Yin, S. Shan, M.S. Ng, L. Yang, D. Mott, W. Fang, N. Kang, J. Luo, C.J. Zhong, Catalytic and electrocatalytic oxidation of ethanol over palladium-based nanoalloy catalysts. Langmuir 29(29), 9249$9258(2013)$

3. Y. Zhang, Q. Yi, H. Chu, H. Nie, Catalytic activity of Pd-Ag nanoparticles supported on carbon nanotubes for the electro-oxidation of ethanol and propanol. J. Fuel Chem. Technol. 45(4), 475-483 (2017)

4. Y. Tao, A. Dandapat, L. Chen, Y. Huang, Y. Sasson, Z. Lin, J. Zhang, L. Guo, T. Chen, Pd-on-Au supra-nanostructures decorated graphene oxide: an advanced electrocatalyst for fuel cell application. Langmuir 32(34), 8557-8564 (2016)

5. M. Liu, Y. Lu, W. Chen, PdAg nanorings supported on graphene nanosheets: highly methanol-tolerant cathode electrocatalyst for alkaline fuel cells. Adv. Funct. Mater. 23(10), 1289-1296 (2013) 
6. A.A. El-Shafei, A.M. Abd Elhafeez, H.A. Mostafa, Ethanol oxidation at metal-zeolite-modified electrodes in alkaline medium. Part 2: palladium-zeolite-modified graphite electrode. J. Solid State Electrochem. 14(2), 185-190 (2009)

7. Z. Zhang, L. Xin, K. Sun, W. Li, Pd-Ni electrocatalysts for efficient ethanol oxidation reaction in alkaline electrolyte. Int. J. Hydrog. Energy 36(20), 12686-12697 (2011)

8. C.W. Xu, H. Wang, P.K. Shen, S.P. Jiang, Highly ordered Pd nanowire arrays as effective electrocatalysts for ethanol oxidation in direct alcohol fuel cells. Adv. Mater. 19(23), 4256-4259 (2007)

9. A.K. Ipadeola, R. Barik, S.C. Ray, K.I. Ozoemena, Bimetallic Pd/ $\mathrm{SnO}_{2}$ nanoparticles on metal organic framework (MOF)-derived carbon as electrocatalysts for ethanol oxidation. Electrocatalysis 10(4), 366-380 (2019)

10. X. Chen, G. Wu, J. Chen, X. Chen, Z. Xie, X. Wang, Synthesis of "clean" and well-dispersive Pd nanoparticles with excellent electrocatalytic property on graphene oxide. J. Am. Chem. Soc. 133(11), 3693-3695 (2011)

11. A. Zalineeva, S. Baranton, C. Coutanceau, G. Jerkiewicz, Electrochemical behavior of unsupported shaped palladium nanoparticles. Langmuir 31(5), 1605-1609 (2015)

12. A. Zalineeva, S. Baranton, C. Coutanceau, G. Jerkiewicz, Octahedral palladium nanoparticles as excellent hosts for electrochemically adsorbed and absorbed hydrogen. Sci. Adv. 3(2), 1-10 (2017)

13. M. Gopiraman, D. Deng, K. Zhang, W. Kai, I. Chung, R. Karvembu, I.S. Kim, Utilization of human hair as a synergistic support for $\mathrm{Ag}, \mathrm{Au}, \mathrm{Cu}, \mathrm{Ni}$, and $\mathrm{Ru}$ nanoparticles: application in catalysis. Ind. Eng. Chem. Res. 56(8), 1926-1939 (2017)

14. C. Kung, P. Lin, Y. Xue, R. Akolkar, L. Dai, X. Yu, C. Liu, Three dimensional graphene foam supported platinum-ruthenium bimetallic nanocatalysts for direct methanol and direct ethanol fuel cell applications. J. Power Sources 256, 329-335 (2014)

15. M. Li, P. Liu, R.R. Adzic, Platinum monolayer electrocatalysts for anodic oxidation of alcohols. J. Phys. Chem. Lett. 3(23), 3480 3485 (2012)

16. Q. Zhang, L. Jiang, H. Wang, J. Liu, J. Zhang, Y. Zheng, F. Li, C. Yao, S. Hou, Hollow graphitized carbon nanocage supported Pd catalyst with excellent electrocatalytic activity for ethanol oxidation. ACS Sustain. Chem. Eng. 6(6), 7507-7514 (2018)

17. J. van Drunen, B. Kinkead, M.C. Wang, E. Sourty, B.D. Gates, G. Jerkiewicz, Comprehensive structural, surface-chemical and electrochemical characterization of nickel-based metallic foams. ACS Appl. Mater. Interfaces 5(14), 6712-6722 (2013)

18. J. van Drunen, B.K. Pilapil, Y. Makonnen, D. Beauchemin, B.D. Gates, G. Jerkiewicz, Electrochemically active nickel foams as support materials for nanoscopic platinum electrocatalysts. ACS Appl. Mater. Interfaces 6(15), 12046-12061 (2014)

19. M. Grden, M. Alsabet, G. Jerkiewicz, Surface science and electrochemical analysis of nickel foams. ACS Appl. Mater. Interfaces 4(6), 3012-3021 (2012)

20. B. Men, Y. Sun, Y. Tang, L. Zhang, Y. Chen, P. Wan, J. Pan, Highly dispersed Ag-functionalized graphene electrocatalyst for oxygen reduction reaction in energy-saving electrolysis of sodium carbonate. Ind. Eng. Chem. Res. 54(30), 7415-7422 (2015)

21. C. Wang, D. Astruc, Recent developments of metallic nanoparticlegraphene nanocatalysts. Prog. Mater. Sci. 94, 306-383 (2018)

22. Y. Li, Y. Zhang, F. Li, M. Li, L. Chen, Y. Dong, Q. Wei, Sandwichtype amperometric immunosensor using functionalized magnetic graphene loaded gold and silver core-shell nanocomposites for the detection of carcinoembryonic antigen. J. Electroanal. Chem. 795, 1-9 (2017)

23. L. Zhang, T. Wu, X. Xu, F. Xia, H. Na, Y. Liu, H. Qiu, W. Wang, J. Gao, Magnetic bimetallic nanoparticles supported reduced graphene oxide nanocomposite: fabrication, characterization and catalytic capability. J. Alloys Compd. 628, 364-371 (2015)
24. K.M. Mayer, J.H. Hafner, Localized surface plasmon resonance sensors. Chem. Rev. 111(6), 3828-3857 (2011)

25. C. Wang, X.G. Nie, Y. Shi, Y. Zhou, J.J. Xu, X.H. Xia, H.Y. Chen, Direct plasmon-accelerated electrochemical reaction on gold nanoparticles. ACS Nano 11(6), 5897-5905 (2017)

26. C. Xu, F. Qin, Q. Zhu, J. Lu, Y. Wang, J. Li, Y. Lin, Q. Cui, Z. Shi, A.G. Manohari, Plasmon-enhanced $\mathrm{ZnO}$ whispering-gallery mode lasing. Nano Res. 11(6), 3050-3064 (2018)

27. A. Kalaiselvi, S.M. Roopan, G. Madhumitha, C. Ramalingam, G. Elango, Synthesis and characterization of palladium nanoparticles using Catharanthus roseus leaf extract and its application in the photo-catalytic degradation. Spectrochim. Acta, Part A 135, 116 119 (2015)

28. V.N. Kalpana, V.D. Rajeswari, Synthesis of palladium nanoparticles via a green route using Lagenaria siceraria: assessment of their innate antidandruff, insecticidal and degradation activities. Mater. Res. Express 5(11), 115406 (2018)

29. J. Feng, P. Zhang, A. Wang, Q. Liao, J. Xi, J. Chen, One-step synthesis of monodisperse polydopamine-coated silver core-shell nanostructures for enhanced photocatalysis. New J. Chem. 36(1), 148-154 (2012)

30. H. Lee, S.M. Dellatore, W.M. Miller, P.B. Messersmith, Musselinspired surface chemistry for multifunctional coatings. Science 318(5849), 426-430 (2007)

31. G. Liu, S. Lu, W. Xu, G. He, Y. Zheng, Y. Cheng, Fabrication of graphene/copper-nickel foam composite for high performance supercapacitors. New J. Chem. 42(12), 9455-9462 (2018)

32. D.C. Marcano, D.V. Kosynkin, J.M. Berlin, A. Sinitskii, Z. Sun, A. Slesarev, L.B. Alemany, W. Lu, J.M. Tour, Improved synthesis of graphene oxide. ACS Nano 4(8), 4806-4814 (2010)

33. D.S. Sheny, D. Philip, J. Mathew, Rapid green synthesis of palladium nanoparticles using the dried leaf of Anacardium occidentale. Spectrochim. Acta Part A 91, 35-38 (2012)

34. S. Sahoo, G. Khurana, S.K. Barik, S. Dussan, D. Barrionuevo, R.S. Katiyar, In situ raman studies of electrically reduced graphene oxide and its field-emission properties. J. Phys. Chem. C 117(10), 5485$5491(2013)$

35. K.N. Kudin, B. Ozbas, H.C. Schniepp, R.K. Prud'homme, I.A. Aksay, R. Car, Raman spectra of graphite oxide and functionalized graphene sheets. Nano Lett. 8(1), 36-41 (2008)

36. B. He, Z. Ren, S. Yan, Z. Wang, Large area uniformly oriented multilayer graphene with high transparency and conducting properties derived from highly oriented polyethylene films. J. Mater. Chem. C 2(30), 6048-6055 (2014)

37. J. Balamurugan, T.D. Thanh, S. Heo, N.H. Kim, J.H. Lee, Novel route to synthesis of $\mathrm{N}$-doped graphene $/ \mathrm{Cu}-\mathrm{Ni}$ oxide composite for high electrochemical performance. Carbon 94, 962-970 (2015)

38. Y. Zhang, M. Park, H.Y. Kim, B. Ding, S.-J. Park, In-situ synthesis of nanofibers with various ratios of $\mathrm{BiOCl}_{\mathrm{x}} / \mathrm{BiOBr}_{\mathrm{y}} / \mathrm{BiOI}_{\mathrm{z}}$ for effective trichloroethylene photocatalytic degradation. Appl. Surf. Sci. 384, 192-199 (2016)

39. Y. Zheng, S. Lu, W. Xu, G. He, Y. Cheng, T. Yu, Y. Zhang, The fabrication of graphene/polydopamine/nickel foam composite material with excellent electrochemical performance as supercapacitor electrode. J. Solid State Chem. 258, 401-409 (2018)

40. Y. Cheng, M. Guo, Y. Yu, M. Zhai, R. Guo, J. Hu, Fabrication of coral-like $\mathrm{Pd}$ based porous $\mathrm{MnO}_{2}$ nanosheet arrays on nickel foam for methanol electrooxidation. Ind. Eng. Chem. Res. 57(32), 10893-10904 (2018)

41. S. Fu, C. Zhu, D. Du, Y. Lin, Facile one-step synthesis of threedimensional Pd-Ag bimetallic alloy networks and their electrocatalytic activity toward ethanol oxidation. ACS Appl. Mater. Interfaces 7(25), 13842-13848 (2015)

42. G. Ren, Y. Liu, W. Wang, M. Wang, Z. Zhang, Y. Liang, S. Wu, J. Shen, Facile synthesis of highly active three-dimensional urchinlike Pd@PtNi nanostructures for improved methanol and ethanol 
electrochemical oxidation. ACS Appl. Nano Mater. 1(7), 32263235 (2018)

43. P. Wu, H. Zhang, Y. Qian, Y. Hu, H. Zhang, C. Cai, Compositionand aspect-ratio-dependent electrocatalytic performances of onedimensional aligned $\mathrm{Pt}-\mathrm{Ni}$ nanostructures. J. Phys. Chem. C 117(37), 19091-19100 (2013)

44. E. Wu, Q. Zhang, A. Xie, W. Yang, C. Peng, J. Hou, Y. He, B. Zhang, L. Deng, Synthesis of hollow echinus-like Au@PdAgNSs decorated reduced graphene oxide as an excellent electrocatalyst for enhanced ethanol electrooxidation. J. Alloys Compd. 789, 174-182 (2019)

45. S. Ye, J. Feng, G. Li, Pd nanoparticle/CoP nanosheet hybrids: highly electroactive and durable catalysts for ethanol electrooxidation. ACS Catal. 6(11), 7962-7969 (2016)

46. Z.X. Liang, T.S. Zhao, J.B. Xu, L.D. Zhu, Mechanism study of the ethanol oxidation reaction on palladium in alkaline media. Electrochim. Acta 54(8), 2203-2208 (2009)
47. Z.R. Yang, S.Q. Wang, J. Wang, A.J. Zhou, C.W. Xu, Pd supported on carbon containing nickel, nitrogen and sulfur for ethanol electrooxidation. Sci. Rep. 7(1), 15479 (2017)

48. F. Ren, H. Wang, C. Zhai, M. Zhu, R. Yue, Y. Du, P. Yang, J. Xu, W. Lu, Clean method for the synthesis of reduced graphene oxidesupported PtPd alloys with high electrocatalytic activity for ethanol oxidation in alkaline medium. ACS Appl. Mater. Interfaces 6(5), 3607-3614 (2014)

49. J. Yang, Y. Xie, R. Wang, B. Jiang, C. Tian, G. Mu, J. Yin, B. Wang, H. Fu, Synergistic effect of tungsten carbide and palladium on graphene for promoted ethanol electrooxidation. ACS Appl. Mater. Interfaces 5(14), 6571-6579 (2013)

Publisher's Note Springer Nature remains neutral with regard to jurisdictional claims in published maps and institutional affiliations. 